2004-02-01

\title{
Laboratory project in wireless FSK receiver design
}

Michael A. Jensen

jensen@byu.edu

Cynthia Fuse

Raymond Woodward

Follow this and additional works at: https://scholarsarchive.byu.edu/facpub

Part of the Electrical and Computer Engineering Commons

\section{Original Publication Citation}

Furse, C., R. J. Woodward, and M. A. Jensen. "Laboratory Project in Wireless FSK Receiver

Design." Education, IEEE Transactions on 47.1 (24): 18-25

\section{BYU ScholarsArchive Citation}

Jensen, Michael A.; Fuse, Cynthia; and Woodward, Raymond, "Laboratory project in wireless FSK receiver design" (2004). Faculty Publications. 455.

https://scholarsarchive.byu.edu/facpub/455

This Peer-Reviewed Article is brought to you for free and open access by BYU ScholarsArchive. It has been accepted for inclusion in Faculty Publications by an authorized administrator of BYU ScholarsArchive. For more information, please contact ellen_amatangelo@byu.edu. 


\title{
Laboratory Project in Wireless FSK Receiver Design
}

\author{
Cynthia Furse, Senior Member, IEEE, Raymond J. Woodward, and Michael A. Jensen, Senior Member, IEEE
}

\begin{abstract}
This paper describes a wireless local area network laboratory project that provides senior and first-year graduate students in microwave engineering courses the opportunity to design, build, and test several passive microstrip components and integrate them into a working system. Students design filters, couplers, amplifiers, diode detectors, quarter-wave transformers, antennas, and stub matching networks in weekly labs that parallel-lectures in a one-semester microwave engineering course. This paper also describes simple inexpensive prototyping and testing methods that have been used in this course. Laboratory materials and technical details of the design are provided on the web for students and educators.
\end{abstract}

Index Terms-Laboratory, microwave engineering, projectbased education, wireless local area network (WLAN).

\section{INTRODUCTION}

$\mathbf{M}$ ICROWAVE engineering courses typically cover topics such as microwave measurement and characterization ( $S$-parameters, reflection coefficients, VSWR, etc.); microwave matching networks, filters, couplers, and power dividers; microstrips, striplines, antennas, waveguides, resonators, amplifiers, and mixers. Given the large volume and wide variety of material, students may leave such a course with a hodgepodge of unrelated concepts and little understanding of how to integrate or use them. If properly exploited, however, this wide range of material provides an excellent opportunity to integrate a full design project into the course that focuses on both component and system-level design and analysis.

Numerous universities include project-based designs in their Electrical Engineering curriculum, and some of these include electromagnetic topics, for example [1]-[2]. This paper adds to the body of relevant modern design projects by describing a frequency-shift-keyed (FSK) receiver laboratory project that supports wireless local area network (WLAN) concepts. This laboratory exercise allows students at Utah State University, Logan, and Brigham Young University, Provo, UT, to design, build, and test individual microwave components and integrate them into a full system during a single-semester Microwave Engineering course [4]. The laboratory course (one-semester credit) complements a traditional Microwave Engineering lecture course (three-semester credits). Eight weeks (five labs) are devoted to designing individual components, and two weeks are devoted to integrating the system. This course is

Manuscript received August 3, 2001; revised June 24, 2002.

C. Furse is with the Department of Electrical and Computer Engineering, University of Utah, Salt Lake City, UT 84112-9206 USA (e-mail: cfurse@ ece.utah.edu).

R. J. Woodward is with the Hewlett-Packard, Fort Collins, CO 80528-9599 USA.

M. A. Jensen is with the Department of Electrical and Computer Engineering,

Brigham Young University, Provo, UT 84602 USA.

Digital Object Identifier 10.1109/TE.2003.816066

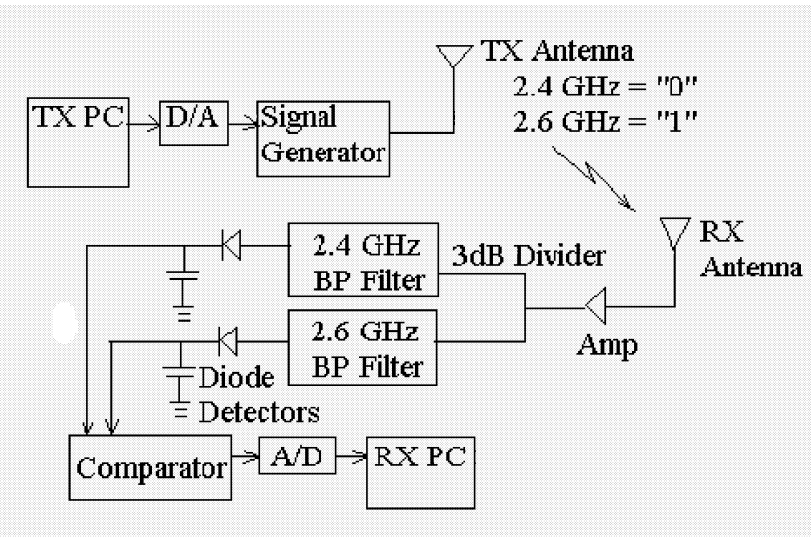

Fig. 1. WLAN block diagram.

taken during the senior year or first year of graduate school. The textbook used is Microwave Engineering by D. Pozar [5]. As a prerequisite for this course, students have taken a single (required junior-level) semester course on introductory electromagnetics. At Utah State University, the introductory course includes brief laboratory exposure to standing waves and single-stub matching networks, Agilent Advanced Design System (ADS) software, and network analyzer measurements. At Brigham Young University, this introductory course also includes a more extensive laboratory project where students build and test a doppler radar [2]. Follow-up courses available to the students after taking Microwave Engineering include a second semester of advanced Microwave Engineering, antenna design, computational electromagnetics, advanced electromagnetic theory, and special topics.

The equipment required for this lab is available in most microwave teaching laboratories or can be acquired for about $\$ 64000$ per bench. One lab bench can be shared by a class of 20 students working in groups of two or three. Simple prototyping methods are used to keep the cost per project to about $\$ 13$. The labs are written deliberately to minimize the equipment required. Utah State University, for instance, has used a single microwave lab bench for the course, which up to 60 students have accessed sequentially. The labs are written with sufficient detail so that after students have become familiar with the microwave test equipment (the first two to three weeks of the labs), they can accomplish the labs with minimal help from the instructor or teaching assistant.

Student feedback from these labs is extremely positive, and the number of students registering for the course has increased markedly since the design projects were introduced. Reports from students indicate that they enjoy the labs, learn considerably from them, gain experience and confidence in system-level design, and more thoroughly understand the concepts in the course. As a spin-off advantage for the instructor, these students 


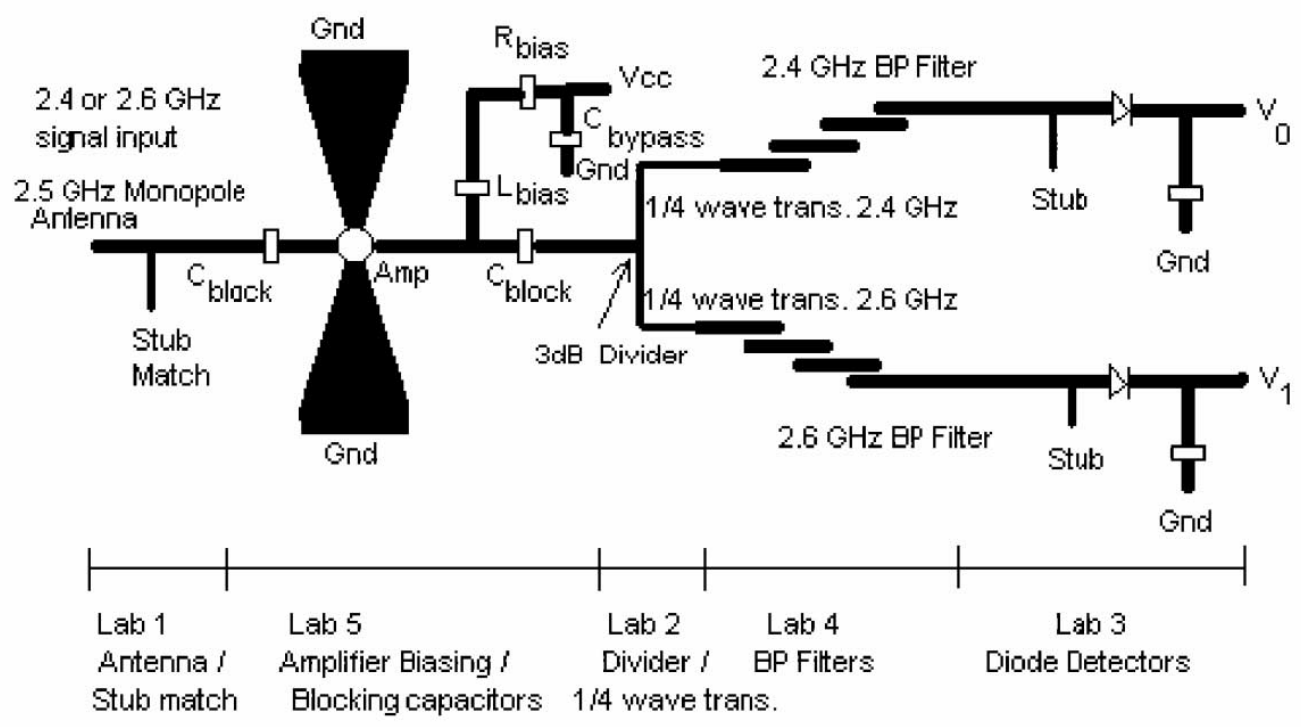

Fig. 2. WLAN layout. Lab 1: Monopole antenna and matching stub(s). Lab 5: Amplifier biasing network and DC blocking capacitors. Lab 2: 3-dB divider and quarter-wave transformers. Lab 4: Bandpass filters. Lab 3: Diode detectors and matching stubs. Lab 6: System integration and test.

are often anxious to pursue senior capstone design projects or graduate projects that include Microwave Engineering and can significantly contribute to related research projects.

\section{FSK RECEIVER PROJECT DESCRIPTION}

Fig. 1 shows a block diagram of the FSK transmitter/receiver system. (A photograph of the finished receiver system is available on the University of Utah website [6].) The basics of an FSK system are explained in [16] and [17]. The concept of this FSK system operation is that a digital " 0 " is transmitted at $2.4 \mathrm{GHz}$, and a digital " 1 " is transmitted at $2.6 \mathrm{GHz}$. The transmission signal is generated by driving either the frequency modulator (FM) input of a commercial synthesized microwave sweeper or the frequency-controlled input of an inexpensive voltage-controlled oscillator (VCO). The student-fabricated receiver then amplifies the signal and splits it into two identical copies using a $3-\mathrm{dB}$ power divider. The narrow-band filters at 2.4 and $2.6 \mathrm{GHz}$ pass or reject, depending on whether the signal was a " 0 " or " 1 ". The signal envelopes are extracted using detectors fabricated from zero-bias Schottky diodes, and the resulting waveforms are run into a comparator whose output voltages are set to those of transistor-transistor logic (TTL). This output signal can then be received by the universal asynchronous receiver-transmitter (UART) of a personal computer and interpreted using acquisition software. Fig. 2 shows the physical layout of the receiver system.

Each block of the receiver system encompasses a week in the laboratory, and most blocks are directly associated with lecture and related homework topics in the course. The individual lab projects are described below and in more detail in [6] and the appendix.

\section{A. Lab 1: Antenna Design and Matching}

The antenna is a simple microstrip-fed wire monopole above a ground plane that is matched using single- and/or double-stub matching. The students design a quarter-wave wire monopole antenna, a $50-\Omega$ microstripline on a given substrate (for the feedline), and single- and double-stub matching networks for the antenna. GIL-3000 laminate [7] is used throughout this project, because it is easy to mill, and the top layer can be easily peeled away by hand, a feature that saves considerable cost in milling bits.

Typical networks provide a return loss of less than $1 \mathrm{~dB}$ at the design frequency of $2.5 \mathrm{GHz}$ and less than $1.5 \mathrm{~dB}$ at 2.4 and $2.6 \mathrm{GHz}$. The stub-matching networks do not always work exactly as designed, presumably because of coupling between the antenna and the stubs/antenna surroundings (including student hands), discontinuities as a result of capacitive solder buildup, and width mismatch between the line and the monopole, and inaccurate fabrication of the matching stubs. Students are often surprised to find other matches that are even better than the ones they designed, such as broad triangular stubs. They will see the effectiveness of nonstandard matching stubs again in the diode detector lab.

\section{B. Lab 2: 3-dB Power Splitter and Quarter-Wave Transformers}

The 3-dB power splitter is a simple T-divider constructed from microstrip line with a $50-\Omega$ input and two $100-\Omega$ output lines. The $100-\Omega$ lines must be matched to the $50-\Omega$ input impedance of the subsequent filters; therefore, quarter-wave transformer sections are used. The impedances of the microstrip lines used to realize the quarter-wave transformers will change very little from 2.4 to $2.6 \mathrm{GHz}$; however, the length (quarter wavelength) will change significantly. Thus, two different transformers are designed, one for 2.4 and one for $2.6 \mathrm{GHz}$. Each transformer is connected to an arm of the power splitter.

In practice (much to the surprise of most students), the $100-\Omega$ lines of the power splitter are never fabricated, since length of these lines is unimportant (and can even be "zero"). The quarter-wave transformers are placed directly adjacent to the power splitter's 50- $\Omega$ input. This placement is depicted in Fig. 3. 


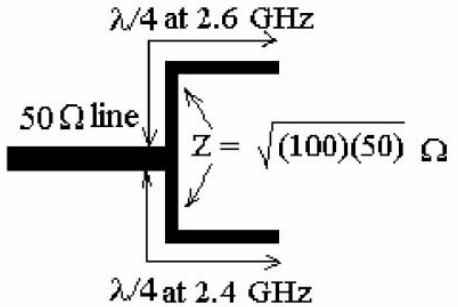

Fig. 3. Detail of T-junction power divider.

The distance between the two transformer outputs is 1 in because that is the size that can be measured by our fixed circuit board holder, which will be described later in the paper.

Only rarely do these quarter-wave transformers not work as expected. Typical theoretical reflection coefficients for the power splitter with both quarter-wave transformers are below $-25 \mathrm{~dB}$ at both 2.4 and $2.6 \mathrm{GHz}$. In the lab, about $-15 \mathrm{~dB}$ is obtained. Theoretical transmission coefficients are typically $-3.04 \mathrm{~dB}$, and measured values are typically -3.3 to $-4.0 \mathrm{~dB}$.

\section{Lab 3: Diode Detectors}

The diode detectors are designed next, since they are relatively easy to explain, and this step gives an extra week for lectures on filters to be completed. The diode detector is a rectifying diode that charges a capacitor to measure the magnitude of the voltage waveform. Students learn how diode detectors work and how to incorporate discrete components (diode and capacitor) using surface mount fabrication techniques. They also design and build a single-stub matching network for the diode detector. This lab introduces the students to the microwave component libraries in the Agilent ADS software, shows them how to create their own components from measured data, and how to use simple surface-mount soldering equipment.

Typical diode detectors have reflection coefficients of between -10 and $-20 \mathrm{~dB}$ (although some well-matched detectors may have reflection coefficients as low as $-40 \mathrm{~dB}$, particularly if students "tune" their stubs by adding triangles of copper tape). When a signal of strength $0 \mathrm{dBm}$ is presented to the detector, about $1 \mathrm{~V}$ is read by the dc voltmeter. Most students are able to make the detectors work the first time, but about $10 \%$ have to be remilled. Most of these "failures" appear to be the result of overheating of components during soldering or poor solder work. The diodes are sensitive to reverse-bias currents and sometimes burn out during testing. Since replacing the diode generally fixes the problem, several extra diodes should be available.

\section{Lab 4: Bandpass Filters}

As shown in Fig. 1, two bandpass filters are required for the project. One must pass $2.4 \mathrm{GHz}$ and reject $2.6 \mathrm{GHz}$, and the other must pass $2.6 \mathrm{GHz}$ and reject $2.4 \mathrm{GHz}$. Students design three-, four-, and five-stage filters, and generally mill four- or five-stage filters. There is considerable leeway in the design criterion, allowing students to center the filters at 2.4 and $2.6 \mathrm{GHz}$, which generally requires five-stage filters, or to center them slightly lower or slightly higher and be able to use four- or even

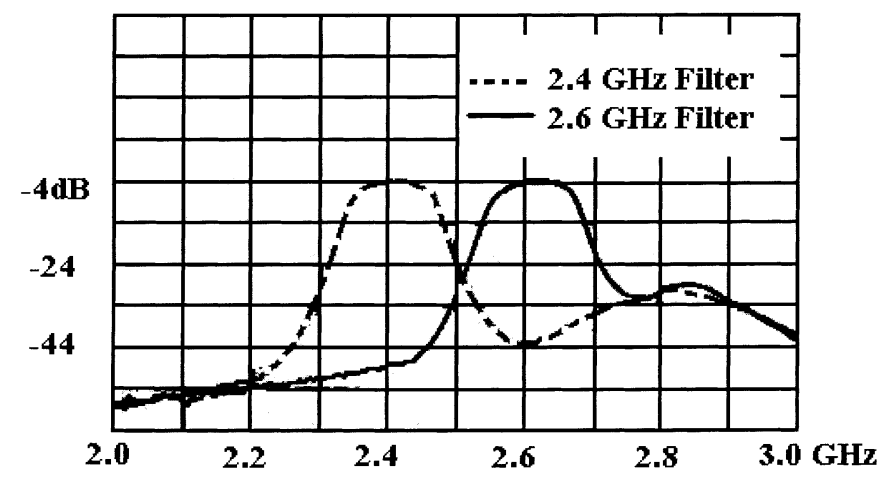

Fig. 4. Typical filter responses.

three-stage filters. They can experiment with flat or rippled passbands and use the "tune" feature of the ADS software to optimize their filter design.

Most students are able to produce filters that work the first time. Typical measured filter responses are shown in Fig. 4. Students who build filters with tight tolerances (the third-order filters), however, sometimes get filters that pass the wrong frequency. In this case, they must redesign and remill the filter.

\section{E. Lab 5: Amplifier}

The amplifier is a commercial ERA-3SM amplifier from Minicircuits, Inc. [9]. The students design and build a biasing network to provide the voltage, current, and grounding required for the amplifier.

The amplifier and biasing circuit are shown in Fig. 2. Because $10 \mathrm{~dB}$ of amplification is necessary to make this circuit function properly, a single-stage amplifier is sufficient. Twoand three-stage amplifiers deliver 30 and $45 \mathrm{~dB}$ of gain, respectively, although the higher stage amplifiers show appreciably more noise and can become unstable if care is not taken during fabrication, biasing, and power supply configuration. In addition, the inductor was not used for the higher stage amplifiers. In this case, the biasing resistor can be connected directly to the signal microstrip in order to reduce the high-frequency loading because of the bias network. An "RF Choke" (also from Minicircuits) can be used in place of the inductor.

\section{F. Lab 6: System Integration and Testing}

All of the parts have been fabricated and tested in the prior five labs. Students are asked to develop a method of connecting the parts so that they can be "debugged" at each connection. The best way is to start at the diode detectors, testing each part, connecting the next part in the circuit, testing, etc.

\section{G. Lab 7: Connection to Computer}

When the circuit response is observed to be correct in Lab 6 , the students are virtually guaranteed success when they connect it to the computers. Students make an appointment with the lab assistant, who helps them connect it to the computer and "checks them off. "Before the system is tested "wireless," it is tested with a cable connecting the transmitter and student-built receiver. The transmitter, which is set up by the lab assistant, 
TABLE I

Parts ReQuired For EACH StUdent ProJect

\begin{tabular}{lll}
\hline Item and Qty & Part Number Used in this Lab & Source \\
\hline Circuit Board & About 1/2 of a 12x18" board of GIL 3000 & {$[5]$} \\
(1) Amplifier & Mini-Circuits ERA-3SM & {$[7]$} \\
(2) Diodes & HP HSMS 2850 & {$[6]$} \\
(5) $100 \mathrm{pF}$ Capacitors (parallel self-resonance $>2.6 \mathrm{GHz})$ & {$[11]$} \\
(1) $47 \mathrm{nH}$ Inductor & (series self-resonance $>2.6 \mathrm{GHz})$ & {$[12]$} \\
(1) $240 \Omega$ 1/2 W Resistor & {$[13]$} \\
Copper Tape with Conductive Adhesive & {$[8]$} \\
\hline
\end{tabular}

uses the PC to modulate the microwave source. The receiver built by the students is connected to an analog-to-digital converter block, which consists of an LM 311 comparator, and finally to the serial input of the receiving computer. The receiver is held by the circuit board holder (described later in this paper) so that a coaxial cable can connect the transmitter [at the radio frequency (RF) output of the signal generator] to the receiver. Details of this circuit are in the lab handouts [6]. The excitement of initial communication is not to be underestimated.

\section{FACILITIES AND EQUIPMENT}

The following is a list of the equipment required for this lab:

Milling machine or etching system (one per lab)

Microwave circuit design software

Agilent ADS was used for this lab

Network analyzer (to $2.6 \mathrm{ghz}$ ) with TRL calibration set

Signal generator (to $2.6 \mathrm{GHz}$ )

Spectrum analyzer (to $2.6 \mathrm{GHz}$ )

Microstrip circuit board holder

Two PCs with RS232 serial ports

Serial communication software

dc voltmeter $(0-2 \mathrm{~V})$

Power supply ( $\pm 12 \mathrm{~V}$ for amplifier)

Surface-mount soldering equipment (one per lab)

Table I provides a list of of parts required for each student project (students work in teams of two to three).

Lab technician time for running the circuit board mill must also be included as a cost of this lab. Approximately $30-40 \mathrm{~h}$ were required for a lab of 30 students (12 groups). Most of this time consisted of weekly "setup time," independent of the number of students. Including this time, the cost per lab group was under $\$ 15$. Inexpensive etching systems are also available at most electronic supply stores and can be used in place of milling.

\section{Microstrip CiRCUIT BOARD HOLDER}

One of the most common problems with microstrip prototypes is poor connections, and hand-soldering of connectors is a common source of these problems. In particular, the receiver described here would have a large number of connectors that would significantly increase the per-student cost and would be a potential source of problems. A circuit board holder was fabricated to eliminate these connectors.

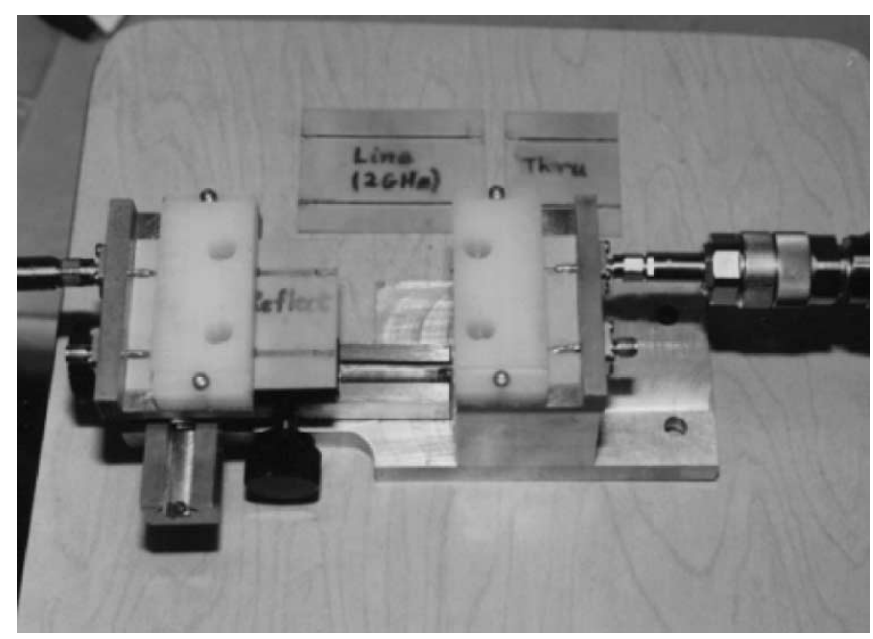

(a)

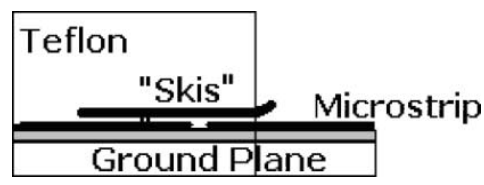

(b)

Fig. 5. Circuit board holder.

The circuit board holder was produced by the Utah State University Industrial Technology Department. It is a low-cost, customized, circuit board holder shown in Fig. 5 (additional photographs are available [6]). This holder has four connections that make it possible to measure three- and four-port devices, such as the coupler. A two-axis optical positioner [9] was used to allow easy adjustment of the ports for measuring longer and shorter boards and for aligning or misaligning the ports, such as for the bandpass filter. The system is built of heavy aluminum for durability, support, and electrical connection of the ground plane. The microstrip boards on the left and right are milled of the same material as the circuits are to be built from, and the only solder connections are to the "SMA" connectors as shown. Teflon blocks hold the circuits firmly in place, and metal "skis" above the microstrip traces ensure electrical contact of the traces. Two holes in each teflon block allow the user to visibly check the alignment of the traces.

The aluminum blocks of the circuit board holder are held in place by screws from below, which can be removed to use each side of the holder independently. This capability is useful when measuring longer circuits (though care must be taken to physically support them) or when measuring single-port devices such as the antennas in Lab 1.

\section{Student Evaluations}

It is difficult to quantify the effect of the new lab on student evaluation scores, since the present instructor (Dr. Furse) has never taught the course without the lab. The student evaluations of this course have been consistently about 5.7/6.0, with average scores for similar classes in the department being 4.8/6.0. The written student comments on the evaluations give a clearer indication. Students unanimously (this is, without exception in four years, approximately 120 students) indicate 
that the project-based approach offered by the WLAN receiver gave them a better understanding of the individual components and how to use them in a microwave system than they would have had without the lab. They asked for more project-oriented classes and more classes in Microwave Engineering. This class serves as a catalyst for student interest and involvement.

\section{CONCLUSION}

The FSK receiver design laboratory described in this paper provides an excellent opportunity for students to learn hands-on component and system-level design, prototyping, testing, and system integration. Each lab is centered on a course topic and provides an opportunity to test and better understand traditional microwave engineering concepts. The integration of the individual lab exercises into a final functional system affords the opportunity to emphasize and understand microwave networks and instills great interest in producing the "best possible" design. The hands-on nature of the course provides experience with state-of-the-art equipment and design software, and students become familiar and confident in their use.

Materials for this laboratory including lab handouts, related lecture notes, and tutorials are available on the web at [6]. A full laboratory handbook is being developed.

\section{APPENDIX \\ DETAILS OF LAB EXPERIMENTS}

\section{A. Lab 1: Antenna Design and Matching}

Prerequisite Knowledge: Many but not all of the students have had a brief exposure to calibration and use of the network analyzer and use of the Hewlett-Packard (HP) ADS design software (or similar software) for analyzing single-stub networks in Introductory Electromagnetics. They also need an understanding of impedance, Smith charts, microstrip transmission lines, wavelength in air and in the microstrip, and singleand double-stub matching networks. These topics are reviewed and/or covered in the first eight lectures of Microwave Engineering. A brief outline of the monopole antenna above ground and its expected input impedance is also provided. Two labs are provided in the first two to three weeks of class to give an overview of the equipment and software for students who would like a review or those (primarily graduate students) who have not previously used the equipment.

Pre-Lab:

1) Students design the $50-\Omega$ microstrip feedline. The lab technician mills the feedlines (using the same size for the whole class, rather than individual files from each student group).

2) Students design a quarter-wave wire antenna above a groundplane.

3) Students design a single- or double-stub matching network (using Smith chart for the ideal case and HP/EEsof ADS circuit design software for the microstrip case).

Lab:

1) Students calibrate the network analyzer using "thru-reflect-load" (TRL) calibration and measure the impedance of several standard components, including an open, short, and matched load.

2) Students attach a wire monopole (slightly longer than the quarter-wave antenna designed) to the microstrip and trim the antenna to get a resonance at exactly $2.5 \mathrm{GHz}$ and measure and verify the impedance of the antenna at 2.4 and $2.6 \mathrm{GHz}$.

3) Students cut (using scissors) copper tape (with conductive adhesive) for the open-circuited stub matching networks, experiment with and optimize the stubs, and measure the final impedance, reflection coefficient, VSWR, etc., of the antenna.

\section{B. Lab 2: 3-dB Power Splitter and Quarter-Wave Transformers}

Prerequisite Knowledge: Students need an understanding of power splitters, quarter-wave transformers, and reflection and transmission coefficients, all of which are covered in lectures. This is the first time most of them have analyzed $S_{21^{-}}$and $S_{12}$-parameters.

Pre-Lab:

1) Students design a $50-\Omega 3$-dB T-junction power splitter for the GIL 3000 substrate.

2) Students design quarter-wave matching sections at 2.4 and $2.6 \mathrm{GHz}$.

3) Students simulate the response of the splitter and transformers for both 2.4 and $2.6 \mathrm{GHz}$.

4) Students prepare layout files for milling. Although most student files end up being the same, and the instructor could feasibly mill the same design for all students, the instructors have allowed students to mill more than one file in this lab and encouraged them to experiment. Many build Wilkinson dividers in addition to the T-junction dividers and compare their responses, and some like to verify for themselves that the $100-\Omega$ T-junction output lines are not needed.

Lab: Students arrive in the lab with their milled power splitter, measure its reflection and transmission coefficients at 2.4 and $2.6 \mathrm{GHz}$, and compare with their expected results. Students also measure the reflection coefficient of the diode that will be used in the next lab. By this time, they are self-sufficient and require little or no assistance from the lab assistant.

\section{Lab 3: Diode Detectors}

Prerequisite Knowledge: Students need a basic understanding of diode detectors and how to use and create component libraries in the simulation software. Diode detectors are described briefly at the beginning of a lecture period, and a data sheet that describes them in detail is given to the students [8]. Since the students are very familiar with the design software by this time (having used it in the previous labs and for several homework assignments), online tutorials are sufficient for them to use and create the component libraries (these tutorials are also provided on the website [6]), and any additional questions are answered briefly in class. A short demonstration of the surface-mount soldering equipment is given in class, and "junk" components and premilled boards 
are provided for students to practice on before soldering their real circuits.

\section{Pre-Lab:}

1) Students compare the standard HP model library for the HP HSMS2850 diode [8], with measurements made the previous week. Students then simulate the diode with capacitor at 2.4 and $2.6 \mathrm{GHz}$.

2) Students design short circuited, single-stub, matching networks for detectors for 2.4 and $2.6 \mathrm{GHz}$. (Short-circuited stubs are used just to give students experience with shorted stubs. Open-circuited stubs, made from copper tape, work equally well.)

3) Students prepare the circuits for milling (including the stubs). Student designs often vary significantly in this lab, as most students use stub-matching networks made from lines other than $50 \Omega$ in order to get broader band matches.

Lab: The students arrive in the lab with their milled boards (for two detectors) ready to solder their surface-mount components.

1) Students surface-mount the diodes and capacitors to build detectors for 2.4 and $2.6 \mathrm{GHz}$ and solder the short circuits for the stubs. (Minimal lab assistant help is needed to conduct this step.)

2) Students measure the reflection coefficient of both diode detectors at 2.4 and $2.6 \mathrm{GHz}$.

3) Students connect the diode detectors to the microwave source and observe the output of the diode detector at 2.4 and $2.6 \mathrm{GHz}$ with an oscilloscope and also with a dc voltmeter.

\section{Lab 4: Bandpass Filters}

Prerequisite Knowledge: Students need a knowledge of bandpass filter design - material covered extensively in lectures and homework.

\section{Pre-Lab:}

1) Students design and optimize two bandpass filters (assigned as a homework during the filter lectures).

2) Students prepare files for milling. Student designs vary widely, and student groups are allowed to build multiple filters for comparison; thus, this lab requires a sizeable amount of lab technician time to do the milling.

$L a b$ : Students arrive in the lab with milled filters, measure the reflection and transmission coefficients of the filters, and compare with expected results. By this time, students need little help from the instructor.

\section{E. Lab 5: Amplifier}

Prerequisite Knowledge: Students need an overview of amplifiers, biasing, and grounding. Amplifier design is not covered in this course; therefore, information is limited to generalities about amplifier design and details of how microwave amplifiers are different from low-frequency amplifiers. Grounding and ground loops are discussed in some detail because this lab provides an excellent demonstration of the concept of distributed, as opposed to point, grounds.
Pre-Lab: Students design the biasing network, prepare files for milling, and surface-mount their components. The amplifier ground is a large triangle extending from the amplifier with many points where grounding pins can be attached (smaller rectangular grounds have also been found to be sufficient, if five to seven ground pins are placed in each ground). Initially, they attach only one grounding pin some distance from the amplifier (which provides a good ground for low-frequency circuits but a poor one for RF networks, as the students will see).

Lab:

1) Students measure the $S$-parameters of the amplifier with poor grounding and with better grounding (adding more ground pins). The amplifier performance is very dependent on this proper grounding, and, therefore, this exercise provides a good demonstration of the effect of grounding.

2) When the amplifier $S$-parameters indicate that it is functioning properly, students connect it to a microwave source and read the amplified output on a spectrum analyzer at 2.4 and $2.6 \mathrm{GHz}$. Alternatively, a network analyzer can automatically measure the performance over a broad frequency range, although the instructors have been hesitant to have students connecting amplifiers to the network analyzer because short circuits to the power supplies can destroy the equipment.

\section{F. Lab 6: System Integration and Testing}

Prerequisite Knowledge: Students need to understand networks of components and how to find the $S$-parameters from devices connected in series (using ABCD parameters and/or ADS software). This material is covered early in the course. Components are connected using copper tape with conductive adhesive, both on the top of the microstrip and on the ground plane [10]. Alternatively, inexpensive coaxial to microstrip transitions can be used to interconnect the individual subcircuits, but experience has shown that this approach results in more connection problems and that the solder joints where the connectors meet the top microstrip tend to break during connection/disconnection, frustrating the students [2]. It is also possible to mill the entire board as a network, which eliminates connectivity issues. However, students can no longer test,verify, or optimize individual components, tune stub matching networks, etc. If components are not working, they cannot be debugged. Some students do a comparison between how their hand-tuned circuit worked and how their nontuned ("off the mill") circuits would have worked in the final design.

Pre-Lab:

1) Using the measured $S$-parameters, students determine the expected performance of the final system.

Lab:

1) Students measure the $S$-parameters of each section of the circuit (diode detector + filter; detector + filter + coupler; etc.) and compare with the expected $S$-parameters.

2) Students test the response of each section of the circuit as it is connected with a microwave source and dc voltmeter at 2.4 and $2.6 \mathrm{GHz}$. 
Detailed Results: If each part of the system works, then connections of each part will work. With $0 \mathrm{~dB}$ of input power to the diode detector, the dc voltmeter reads about $1 \mathrm{~V}$. When the filter is added to the detector, about $0.7 \mathrm{~V}$ will be output at the frequency of the filter, and less than $0.2 \mathrm{~V}$ will be output at frequencies in the stop bands. When the coupler is added, about $0.5 \mathrm{~V}$ will be output at the desired frequency, less than $0.1 \mathrm{~V}$ for stop frequencies. When the amplifier is added, the input power is reduced to $-10 \mathrm{~dB}$, and the observed dc values should remain about the same (most amplifiers had about $10 \mathrm{~dB}$ of gain). The antenna is not connected to the circuit at this point because the students need another antenna in order to test the circuit with an antenna. Although issues such as accurate antenna pointing could be incorporated into the lab, the authors have not included that work in their labs. When problems with the circuit occur, they are most often because of poor connection of the copper tape (usually sloppiness or being "unstuck" too many times). Occasionally, a diode or amplifier has stopped working (usually marginal soldering that has been bumped and come loose).

\section{G. Lab 7: Connection to Computer}

Prerequisite Knowledge: Students benefit by understanding the computer connection. The assumption is that the students can understand the circuit diagram which is handed out in class from knowledge obtained during their beginning digital logic and computer architecture course-material not reviewed in this course.

Pre-Lab: Students are asked to write a description of the transmitter and receiver systems and how each part functions to produce and receive the desired signal.

Lab and Results: Students connect their system to the computer, substituting a wire for the "wireless channel" and, after debugging any errors, are able to type messages from one computer to the other. They can experiment with the baud rate (a baud rate of $1100 \mathrm{~b} / \mathrm{s}$ is as high as the current system can achieve). They then replace the "wire" with the antennas and communicate "wireless," again varying the baud rate. The monopole antenna they designed is connected to the receiver, and another antenna (instructors have used an additional monopole, a horn, a discone, and a microstrip antenna array, all successfully) is connected to the transmitter. As a further development, students taking the (separate) antenna course can design a set of directional antennas for use with the system. With simple wire antennas, baud rates from 50-300 b/s have been obtained. If some parts of the system (such as the filters) were marginal, they can be swapped for a part from a more successful group. The excitement of initial communication is not to be underestimated.

\section{ACKNOWLEDGMENT}

This lab was originally developed at Brigham Young University by $\mathrm{M}$. A. Jensen. It was adapted and redesigned at Utah State University by C. Furse and R. J. Woodward. A circuit board holder was originally designed at University of Utah and was redesigned and built at Utah State University by R. Nielsen,
Department of Industrial Technology and Education. The tutorials for Agilent ADS were written by C. Furse, N. Kamdar, and R. J. Woodward. The tutorial for the circuit board mill was written by A. Esplin. Generous equipment support from Hewlett-Packard Corporation (now Agilent Technologies) has made this lab possible.

\section{REFERENCES}

[1] T. Weller, P. Flikkema, L. Dunleavy, H. Gordon, and R. Henning, "Educating tomorrow's RF/microwave engineer: A new undergraduate laboratory uniting circuit and system concepts," presented at the IEEE MTT-S Int. Microwave Symp., Baltimore, MD, June 1998.

[2] M. A. Jensen, D. V. Arnold, and D. E. Crockett, "Microwave engineering design laboratories: $C$-band rail SAR and Doppler radar systems," 1999 IEEE AP-S Int. Symp. Dig., vol. 1, pp. 82-85, July 1999.

[3] E. W. Bryerton, W. A. Shiroma, and Z. B. Popovic, "An active microstrip circuits lab course," 1997 IEEE AP-S Int. Symp. Dig., vol. 4, pp. 2490-2493, July 1997.

[4] C. Furse, "Hands-on electromagnetics-Microstrip circuit and antenna design laboratories at USU," presented at the 1999 IEEE Antennas Propagation/ URSI Int. Symp., Orlando, FL, July 1999.

[5] D. M. Pozar, Microwave Engineering, 2nd ed. New York: Wiley, 1998.

[6] (2002, July). [Online]. Available: http://www.ece.utah.edu/ cfurse/microwave/LECTURE/LAB/labinfo.html

[7] Gil Laminates, Collierville, TN.

[8] Technical Data for Hewlett-Packard HSMS 2850 Schottky Detector Diodes (2002, July 30). [Online]. Available: http://www.semiconductor.agilent.com, search for hsms 2850

[9] (2002, July). Mini-Circuits Inc., Brooklyn, NY. [Online]. Available: http://www.minicircuits.com

[10] (2002) Copper Foil With Conductive Adhesive 3M 1181. 3M, Inc., Electrical Products Div. [Online]. Available: http://www.3m.com

[11] Two-Axis Movement, pt. P3683, Edmund Scientific, Inc..

[12] M. Baird, private communication, University of Utah, Salt Lake City, UT.

[13] "100 pF Capacitors With Parallel Self-Resonance Above $2.6 \mathrm{GHz}$," Kemet, Inc, CO805C101J5GACTR, case size 0805.

[14] "47 nH Inductors With Parallel Self-Resonance Above $2.6 \mathrm{GHz}$," Draloric, Inc., Mini Melf SIM-0204.

[15] $240 \Omega 350 \mathrm{~mW}$ Resistor RCW5150 (02, 7 30). [Online]. Available: http://www.vishay.com

[16] T. S. Rappaport, Wireless Communications. Englewood Cliffs, NJ: Prentice-Hall, 1996, ch. 5.

[17] D. Pozar, Microwave and RF Design of Wireless Systems. New York: Wiley, 2001, ch. 9.2.

Cynthia Furse (S'85-M'87-SM'99) received the B.S. degree in electrical engineering with a mathematics minor, the M.S. degree in electrical engineering, and the Ph.D. degree in electrical engineering from the University of Utah, Salt Lake City, in in 1985, 1988, and 1994, respectively.

She is currently an Associate Professor with the University of Utah and has taught electromagnetics, wireless communication, computational electromagnetics, microwave engineering, antenna design, and introductory electrical engineering. She has a great interest in the development of project-based curricula, which she applied during five years of teaching at Utah State University, Logan. She works to interest young students, particularly women and minorities, in engineering and routinely volunteers in Utah's K-12 schools as an engineering mentor, science educator, and engineering career guidance counselor. She is also active with the Society of Women Engineers, Junior Engineering State, Expanding Your Horizons, School-to-Careers, MESA, Girl Scouts, and Boy Scouts. She is the Director of the Center of Excellence for Smart Sensors, an active funded research program, including electromagnetics for biology and remote sensing. She has been an NSF CISE Graduate Fellow, IEEE Microwave Theory and Techniques Graduate Fellow, and President's Scholar at the University of Utah. She is the author of more than 30 publications in refereed engineering journals, six invited tutorials, and more than 45 conference presentations.

Dr. Furse was the Professor of the Year in the College of Engineering, Utah State University, for the year 2000. 
Raymond J. Woodward received the B.S. degree in electrical engineering (magna cum laude), with minors in math, computer science, physics, and Portuguese, and the M.S. degree in electrical engineering from Utah State University (USU), Logan, in 1999 and 2000, respectively. His thesis consisted of the development and implementation of a water-level sensor using frequency domain reflectometry.

He received a Presidential Scholarship from USU for his undergraduate work and a Presidential Fellowship from USU for his graduate work. Currently, he is with Hewlett-Packard, Fort Collins, CO, where he is a Design Engineer developing mid-range servers.

Mr. Woodward is a Member of Tau Beta Pi.
Michael A. Jensen (S'93-M'95-SM'01) received the B.S. (summa cum laude) and M.S. degrees in electrical engineering from Brigham Young University (BYU), Provo, UT, in 1990 and 1991, respectively, and the Ph.D. degree in electrical engineering from the University of California, Los Angeles (UCLA), in 1994.

From 1989 to 1991, he was a Graduate Research Assistant in the Lasers and Optics Laboratory at BYU. In 1990 he received a National Science Foundation Graduate Fellowship. From 1991 to 1994, he was a Graduate Student Researcher in the Antenna Laboratory at UCLA. Since 1994, he has been with the Electrical and Computer Engineering Department at BYU, where he is currently an Associate Professor. His main research interests include antennas and propagation for personal communications, microwave circuit design, radar remote sensing, numerical electromagnetics, and optical fiber communications.

Dr. Jensen is a Member of Eta Kappa Nu and Tau Beta Pi. 